\title{
Seroprevalence of $\mathrm{HBV}$ and $\mathrm{HIV}$ co-infection in children and outcomes following highly active antiretroviral therapy (HAART) in Uyo, South-South Nigeria
}

\author{
*Ikpeme EE ${ }^{1}$, Etukudo $\mathrm{OM}^{1}$, Ekrikpo $\mathrm{UE}^{2}$
}

1. Department of Paediatrics, University of Uyo Teaching Hospital -PMB 1136 Uyo Akwa Ibom State, Nigeria

2. Department of Internal Medicine University of Uyo Teaching Hospital, Uyo, Akwa Ibom State, Nigeria

\begin{abstract}
Background: Human Immunodeficiency Virus/ Hepatitis B Virus (HIV/HBV) co-infection in Nigerian children has emerged as a major concern with the advent of HAART. Its impact on the immune system and liver has not been extensively studied in children.

Objectives: To determine the prevalence of HBV seropositivity among HIV positive children on HAART and its effect on immune response and liver enzymes.

Methods: All consecutive HIV positive children aged two months to seventeen years on HAART constituted the study population. Age and gender; CD4+ count, ALT, creatinine and HBsAg were tested and documented at enrolment and 12 months.

Results: One hundred and seventy one patients were seen over this period. Seventy-two (43.4\%) were males while 94 $(56.6 \%)$ were females giving a male: female ratio of $1: 1.3$. The mean age of the patients was $63 \pm 43.4$ months. Prevalence of HIV/HBV co-infection was 6.02\% (95\% CI 2.4-9.7). There was no significant effect of HBV status on elevation of ALT levels with 12 months of HAART. Co-infected patients had an odds ratio of achieving immune response of 0.14 (95\% CI $0.02-0.79)$.

Conclusion: $\mathrm{HIV} / \mathrm{HBV}$ co-infection rates in our children are comparable to other localities. ALT levels do not worsen with HAART and immune response of the co-infected children on HAART is lower.

African Health Sciences 2013; 13(4): 955 - 961 http://dx.doi.org/10.4314/ahs.v13i4.14
\end{abstract}

\section{Introduction}

Nigeria has the greatest burden of paediatric HIV/ AIDS in sub-Saharan Africa despite a national seroprevalence of $4.6 \%{ }^{1,2}$ There are over 240,000 children living with HIV/AIDS, representing 15\% of the African burden. ${ }^{3}$ The rate of vertical transmission is as high as $25 \%-42 \%$ in African countries. An estimated 600,000 new paediatric infections occur each year, with over $90 \%$ of these cases occurring in sub-Saharan Africa. ${ }^{4}$ Rapid progression of HIV-1 infection to Acquired Immune Deficiency Syndrome (AIDS) is also a major problem in these children. Up to $25 \%$ of prenatally infected infants progress to AIDS within one year

\begin{tabular}{|l|}
\hline *Corresponding author: \\
Ikpeme Enobong Emmanuel \\
Department of Paediatrics \\
University of Uyo Teaching Hospital \\
PMB 1136 Uyo Akwa Ibom State \\
Nigeria \\
T: 2348033123336 \\
Email: enpeks@yahoo.com \\
\hline
\end{tabular}

African Health Sciences Vol 13 Issue 4 December 2013 and the remaining $75 \%$ within a median period of seven years. ${ }^{5}$

Nigeria belongs to the group of countries highly endemic for hepatitis B virus (HBV) infection, ${ }^{6}$, ${ }^{7}$ a virus that shares common modes of transmission with HIV. ${ }^{8}$ One of the major determinants of accelerated HIV disease progression is the presence of co-morbidities and opportunistic infections. The epidemiology, natural history and treatment of HIV co-infection with HBV has been studied extensively in adults ${ }^{9-13}$ and documented sparingly in children, ${ }^{14-}$ ${ }^{16}$ more so among Nigerian children. In Tanzania and Cote d'Ivoire, the prevalence rates of the coinfection has been reported as $1.2 \%{ }^{14}$ and $12.1 \%{ }^{17}$ respectively while among Nigerian children, it is $8.3 \%$. 18

HBV infection is known to lead to chronic infection after the acute infection especially if acquired in the perinatal period and early childhood. ${ }^{6,19}$ With improved survival due to the success of highly active antiretroviral therapy (HAART), chronic viral hepatitis has become a major source of co morbidity in HIV infected populations. ${ }^{20}$ In adults, co-infection 
with $\mathrm{HBV}$ increases the risk for hepatotoxicity of HAART and likelihood of onset of an AIDSdefining illness, compared to infection with HIV-1 alone. ${ }^{21}$ It is not certain whether this is the case with children.

Most studies on co-infection in Nigeria have been in adults. With increasing access to HAART in Nigeria, it is expected that more HIV infected and co-infected children will survive. Although HIV coinfection with HBV has been recognised worldwide, there is limited data on the impact of this co-infection on the immune system. Data on its effect on the liver with HAART is also limited in developing countries like Nigeria. It is therefore imperative that the burden of this co-infection is quantified and its attendant effect investigated.

This study was therefore carried out to determine the prevalence of HBV seropositivity in a cohort of paediatric patients living with HIV/AIDS in a tertiary hospital in south-south Nigeria. The effect of co-infection on CD4+ lymphocytes and liver enzymes in the HAART era were also examined.

\section{Methods}

This prospective longitudinal study was conducted in the Infectious Disease Unit (IDU) of the Department of Paediatrics, University of Uyo Teaching Hospital (UUTH), Uyo, from December 2010 to August 2011. The hospital is the only tertiary and referral centre in Uyo, capital city of Akwa Ibom State of Nigeria. It is also the main centre for Paediatric HIV care. It serves the 3.9 million population of the State.

The study was approved by the University of Uyo Teaching Hospital Research and Ethics Committee.

The IDU runs a weekly Paediatric HIV/ AIDS clinic. It is one of the President's Emergency Plan Funds for AIDS Relief (PEPFAR) sites where antiretroviral drugs are given and investigations are carried out at no cost to the patient. The baseline investigations that are conducted before commencement of HAART include CD4+ count, full blood count, electrolytes, creatinine, urea, and liver function tests. Eligibility criteria for commencement of HAART included all children less than 24 months irrespective of the CD4+ cell count; CD4+ cell count $<750$ in children aged 25 months to 59 months, $<350$ for 60 months and above and any child seen at clinical stage 3 or 4 .

Eligible patients were commenced on HAART and were seen on a regular basis at the clinic.
HAART comprised at least two drugs from the Nucleoside reverse transcriptase inhibitor (NRTIs) class of antiretroviral drugs and one from the Nonnucleoside reverse transcriptase inhibitor class (NNRTIs). The first line drugs used included Lamivudine (3TC), Zidovudine (AZT) and Nevirapine (NVP) as fixed dose combination. At follow up visits, they received general paediatric care with full physical examination and anthropometric measurements taken. Their CD4+ counts and full blood count were monitored on a 3-monthly basis, while electrolytes, creatinine, urea and liver function tests were monitored biannually. All consecutive children aged two months to seventeen years that were confirmed to be HIV positive during the study period were enrolled.

Informed consent was obtained from the parent/guardian prior to enrolment. Children older than 10 years also gave a verbal consent. Confirmation was by enzyme - linked immunosorbent assay (ELISA) in those older than 18 months or by DNA polymerase chain reaction (PCR) for those younger than 18 months. HIV RNA viral load and HBV DNA viral load were not done as our facility didn't have the equipment for these tests at the time of the study.

All children that were not eligible for HAART (five in all) were excluded from subsequent analysis after the prevalence of co-infection among the HIV positive was obtained. CD4+ cell count and $\mathrm{HBsAg}$ tests were done at enrolment and one week after if they were eligible for HAART, and baseline investigations were carried out. Thereafter, the patients had an average of three adherence counselling sessions within a period of two weeks before initiation of HAART.

Demographic information (age and sex), results of investigations (CD4+ count, alanine aminotransferase, and creatinine) were obtained and documented.

HBsAg was tested using First Response Rapid HBsAg test (Blumber B. S. 1991, San Diego, USA). For CD4+ count, Flow Cytometry using Partec cyflow counter (Greve, B. Et al 2003, Germany) was used. All the chemistry was done using the in vitro quantitative analysis method using Vitros DT 6011 chemistry system (Johnson \& Johnson). All assay protocols, cut-offs and interpretation were according to the manufacturer's instructions. 
A gender comparison of the clinical, biochemical characteristics and HBV prevalence of the participants was done. The prevalence of HBV in each of the age groups was also explored. The proportion of those with elevated ALT levels $(>2$ times upper limit of reference range for our laboratory which was $70 \mathrm{iu} / 1$ ) by co-infection status was computed and univariate and multivariate logistic regression models were used to investigate the effect of HBV status on having elevated serum ALT at commencement of HAART. Immune response was defined as the achievement of at least 50 cells $/ \mu \mathrm{L}$ increments in CD 4 count from baseline at 12 months of therapy. The effect of co-infection on achieving immune response was also investigated using multivariate logistic regression. All factors with a pvalue of the Wald statistic $<0.25$ at univariate analysis or known to have potential effect on immune response were included in the multivariate model built using stepwise regression.

\section{Results}

One hundred and sixty six (166) paediatric patients were seen over this period. Seventy - two (43.4\%) were males while $94(56.6 \%)$ were females giving a male:female ratio of $1: 1.3$. The mean age of the patients was $63 \pm 43.4$ months. The mean duration on Highly active antiretroviral therapy (HAART) was 24.2 \pm 18.1 months. Table 1 shows the baseline characteristics of the study participants. Those aged 2- 23 months were 30 (18.1\%), 24 - 60 months were $67(40.4 \%), 61-120$ months $48(28.9 \%)$ and $>120$ months were 21 (12.6\%).

\section{Prevalence of HIV-HBV co-infection}

Ten $(6.02 \%)$ (95\% CI 2.4 to $9.7 \%$ ) of the patients had HIV - HBV co-infection. There was no significant difference in the prevalence of $\mathrm{HBV}$ in both genders. Four (5.8\%) of the females were HBV positive compared to $6(6.7 \%)$ of the males, $\mathrm{p}=$ 0.54 . With regards to age groups, the highest prevalence was found in the 10 years group $(11.5 \%)$, followed by the 5 - 10 years age group $(9.3 \%)$. There was no association between age and HBV co -infection $(p=0.47)$. A comparison of the sociodemographic and clinical characteristics of those with HIV-HBV co-infection with those with only HIV infection is shown in Figure 1 and table 2. Individuals with $\mathrm{HBV}$ co-infection had higher serum creatinine levels and lower $\mathrm{CD} 4$ cell counts at baseline and at 12 months of therapy.

\section{Table 1: Gender distribution of baseline characterisitics}

\begin{tabular}{lllll}
\hline & Total & Male & Female & p - value \\
\hline Age & $63.0 \pm 43.4$ & $61.9 \pm 41.1$ & $64.3 \pm 46.4$ & 0.75 \\
ALT (U/L) & $42(31-58)$ & $38.5(29-56)$ & $45(34-60)$ & $0.12^{*}$ \\
Creatinine (umol/L) & $44.5 \pm 20.1$ & $44.5 \pm 20.7$ & $44.4 \pm 19.3$ & 0.98 \\
Baseline CD4 count(cells/uL) & $503(233-860)$ & $468(232-822)$ & $591.5(264.5-957)$ & $0.44^{*}$ \\
\hline
\end{tabular}

*Wilcoxon rank sum test.
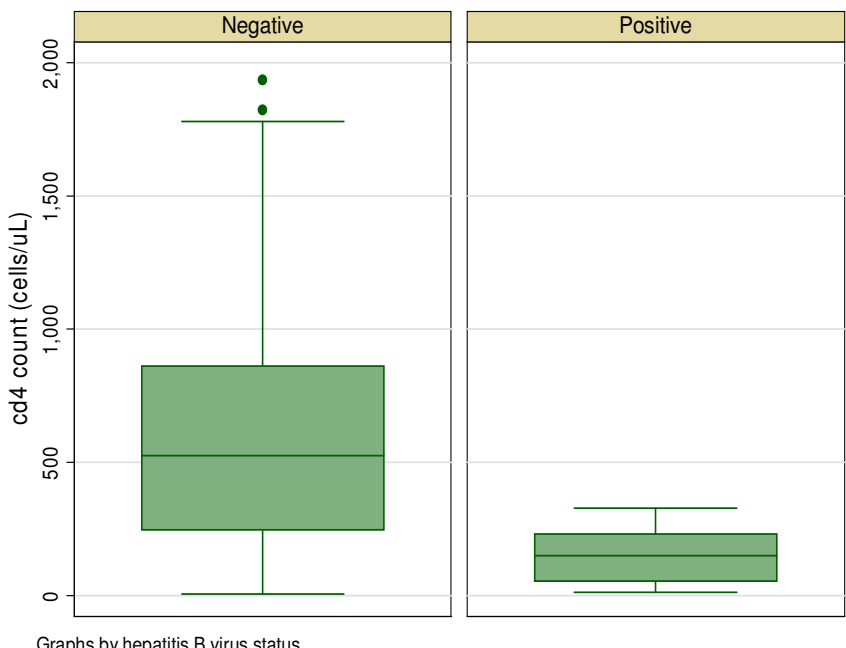

Graphs by hepatitis B virus status

Figure 1: Graph box showing CD4 count by HBV status 
Table 2: Comparison of sociodemographic and clinical characteristics by HBV status

\begin{tabular}{llll}
\hline & \multicolumn{2}{l}{ Hepatitis B status } & \multirow{2}{*}{ p - value } \\
\cline { 2 - 3 } & Negative & Positive & \\
\hline Male gender (n/\%) & $83(56.1)$ & $6(60)$ & 0.81 \\
Age (months) & $61.8 \pm 42.5$ & $83.9 \pm 49.9$ & 0.12 \\
ALT (U/L) & $42(31-56)$ & $50(30-70)$ & 0.49 \\
Creatinine (umol/L) & $42.5(32-50)$ & $54.5(45-56)$ & 0.02 \\
CD4 count at baseline (cells/uL) & $529(249-861)$ & $149(53-232)$ & 0.0003 \\
CD4 count at 6 months of HAART & $893(560-1245)$ & $318(83-566)$ & 0.0004 \\
\hline
\end{tabular}

Influence of Hepatitis B status on ALT levels At the commencement of HAART, $66(39.8 \%)$ of the children had elevated serum ALT levels; (70\% of the co-infected children and $58.1 \%$ of the HIV only group ) but this difference was not statistically significant $(p=0.46)$. Only four of the children had ALT levels greater than two times the upper limit of normal and all were Hepatitis B negative. A multivariate logistic regression model did not show any significant effect of HBV status on development of elevated ALT levels one year after commencement of HAART (see table 3). However, male gender appeared to be protective against having elevated ALT levels and those with elevated ALT levels at commencement of HAART were more prone to developing higher ALT levels while on therapy.
Influence of $\mathrm{HBV} / \mathrm{HIV}$ co-infection on immune response

Seventy percent of the co-infected and $84.5 \%$ of the mono-infected patients achieved immune response at 12 months of therapy. A second logistic regression model was used to assess the effect of HBV/HIV co-infection on achievement of immune response. The findings are summarized in Table 4. Those with HIV/HBV co-infection have an odds ratio of achieving immune response of 0.14 (95\% CI $0.02-$ 0.79) after correcting for CD4 count at baseline, age, gender, BMI, ALT and serum creatinine levels.

Table 3: Association between elevated ALT level and HBV status

\begin{tabular}{lll}
\hline & $\begin{array}{l}\text { Univariate } \\
\text { Odds ratio (95\%) CI, } \\
\text { p - value }\end{array}$ & $\begin{array}{l}\text { Multivariate } \\
\text { Odds ratio (95\%) CI, } \\
\text { p - value }\end{array}$ \\
\hline Positive HBV status & $1.74(0.48-6.29)$ & 0.40 \\
Male gender & $0.14(0.07-0.29)<0.001$ & $0.97(0.08-12.58) 0.98$ \\
Age (months) & $1.00(0.99-1.01) 0.94$ & $0.01(0.002-0.07)<0.001$ \\
CD4 count at baseline (100 cells/UL) & $0.99(0.98-1.00) 0.24$ & $0.99(0.97-1.01) 0.33$ \\
Serum creatinine (umol/L) & $1.00(0.98-1.02) 0.58$ & $0.98(0.97-0.99) 0.048$ \\
ALT (U/L) & $1.11(1.07-1.15)<0.001$ & $1.00(0.97-1.04) 0.11$ \\
\hline
\end{tabular}

*The area under the Receiver Operator Characteristic (ROC) Curve of the model was 0.82

Table 4: Univariate and Multivariate logistic models for predictors of immune response

\begin{tabular}{|c|c|c|}
\hline & $\begin{array}{l}\text { Univariate } \\
\text { Odds ratio }(95 \% \mathrm{CI}) \text { p-value }\end{array}$ & $\begin{array}{l}\text { Multivariate* } \\
\text { Odds ratio }(95 \% \mathrm{CI}) \text { p-value }\end{array}$ \\
\hline Positive $\mathrm{HBsAg}$ & $0.43(0.10-1.78) 0.24$ & $0.14(0.02-0.79) 0.03$ \\
\hline CD4/100 cells $/ \mu \mathrm{L}$ & $0.98(0.97-0.99)<0.001$ & $0.98(0.97-0.99)$ \\
\hline Female gender & $0.9590 .41-2.21) 0.91$ & $0.58(0.20-1.66) 0.31$ \\
\hline $\operatorname{ALT}(\mathrm{U} / \mathrm{L})$ & $1.01(0.99-1.03) 0.25$ & $1.01(0.98-1.03) 0.54$ \\
\hline BMI & $1.01(0.84-1.21) 0.93$ & $1.08(0.85-1.35) 0.58$ \\
\hline Age (months) & $1.01(0.99-1.02) 0.25$ & $1.00(0.99-1.02) 0.65$ \\
\hline Creatinine $(\mu \mathrm{mol} / \mathrm{L})$ & $0.99(0.97-1.01) 0.26$ & $0.98(0.96-1.01) 0.16$ \\
\hline
\end{tabular}




\section{Discussion}

HAART has transformed HIV/AIDS from a uniformly fatal illness into a manageable chronic infection and has been shown to be able to restore CD4+ cells in HIV infected patients. ${ }^{22}$ The gains of HAART could be compromised by co-infection with hepatitis viruses as they are known to have adverse effects on the prognosis of HIV and hepatitis infections. ${ }^{23}$ Consequently, increased attention has to be paid to co-infection of hepatitis viruses and HIV.

In this study, the HIV/HBV co-infection rate of $6.02 \%$ is comparable to the $7.7 \%$ and $8.3 \%$ obtained from other Nigerian studies. ${ }^{18,24} \mathrm{It}$ is however lower than the $12.1 \%{ }^{17}$ from a neighbouring west African country of Cote d' Ivoire but higher than rates of $1.2 \% 0^{14}$ and $4 \%{ }^{13}$ from some east African countries. A study from Bronx, New York reported a prevalence of $2.6 \% .{ }^{16}$ These differences may reflect the seroprevalent rates of $\mathrm{HBsAg}$ in the different populations. Although some Nigerian studies quoted $\mathrm{HBsAg}$ rates as high as $44.7 \%$, the inclusion of Hepatitis B vaccine in the National Programme on Immunization (NPI) in the past decade has reduced the population prevalence and consequently reduced the HIV/HBV co-infection prevalence.

The finding that the mono and co-infected patients shared similar demographic characteristics with respect to age and sex was also reported by other authors. ${ }^{14,16,24}$ The mean age of the co-infected patients, however, was higher in this study. The Bronx, New York study also identified more adolescents to be co-infected. This may be attributed to the fact that children in this age group were exposed before the current prevention strategies were available( inclusion of HBV in the NPI schedule in 2004). In contrast, Sadoh and coworkers ${ }^{24}$ concluded that immunization did not make any significant difference in the prevalence of co-infection. This conclusion, however, is presumptuous because they analysed only the hepatitis B immunization history of the under-five instead of the whole study population.

The higher level of the liver enzyme, alanine aminotransferase (ALT) in the co-infected group was also reported by other workers. ${ }^{14,16}$ This is expected since hepatitis viruses are known to elevate liver enzymes. ${ }^{26}$ We found no association between HAART and elevated ALT. This is similar to the findings of Telatela et al ${ }^{14}$ and Toussi et al ${ }^{16}$ but contrasts reports from other studies. ${ }^{27-29}$ Our patients were on first line regimen which comprises lamivudine, zidovudine and nevirapine. It has been reported that lamivudine as a component of HAART, has a beneficial effect in that it causes inhibition of HBV replication in adherent patients ${ }^{8}$. Other drugs that have this beneficial effect are tenofovir and emtricitabine ${ }^{30}$. On the contrary, patients on protease inhibitors are at risk of developing a worsening of the liver disease since they are associated with more risk of elevated ALT than other antiretroviral drugs. ${ }^{29}$

As reported by other authors ${ }^{14,16}$ in their study of paediatric patients, our co-infected patients had significantly lower CD4+ cell counts compared to the mono-infected group. However, these authors did not study the effect of HAART on the CD4 cell count. We noted that the co-infected patients were less likely to achieve immune response even with HAART for one year. This calls for establishment of a treatment protocol for HIV/HBV co-infected patients which includes at least two of the antiretroviral drugs that induce suppression of $\mathrm{HBV}$ replication, as first line regimen. This will reduce the hepatotoxic effect of the viruses, improve immune response as well as prevent development of resistance on prolonged use of lamivudine alone.

In contrast, in the adult population, Lincoln and co-workers ${ }^{31}$ on behalf of the Australian HIV Observational Database, reported that co-infection with HBV did not appear to influence CD4 count recovery following commencement of HAART. Their work involved a larger group of participants (2089) and the immune response was also checked after 12 months of HAART. Our study appears to be the first to examine this issue in Nigerian children.

\section{Conclusion}

We have demonstrated that co-infection of HIV with HBV exists in our local at rates that are comparable with those of other communities. We have also shown that HAART does not worsen ALT levels and that the immune response of the co-infected patients is lower with treatment compared to the mono-infected patients.

\section{Recommendations}

We therefore recommend that screening for HBsAg be mandatory in all paediatric HIV patients in our environment, especially the adolescents. They should receive special attention with regards to, the antiretroviral drugs they are treated with, monitoring and follow up to assess disease progression. 
The limitations of this study include the inability of our laboratory to carry out HIV RNA viral load and the HBV DNA viral load. Further studies with determination of viral loads are advocated.

\section{References}

1. National Agency for the Control of AIDS. United Nations General assembly Special Session (UNGASS) Country Progress Report Nigeria. Reportin Period January 2008- December2009 http://www.unaids.org/fr/dataanalysis / monitoring countryprogress / 2010 progressreporttssubmittedbycountries / file,33651,fr..pdf (accessed 20 January 2012).

2. United Nations Children's Fund. State of the World's Children. New York: 2009.

3. Federal Ministry of Health, Nigeria. National Guidelines for Paediatric HIV and AIDS treatment and care. Abuja, Nigeria, 2007.

4. Joint United Nations Programme on HIV/AIDS (UNAIDS) and World Health Organization (WHO) AIDS epidemic update: December 2006. Available at: http://www.unaids.org/en/HIV data 2007 Epi Update/default.asp. Accessed 25 January 2012.

5. Konopricki D, Mocroft A, deWit S. Hepatitis B and HIV : prevalence, AIDS progression, response to HAART and increased mortality in the EuroSIDA cohort. AIDS 2005; 19:593-601.

6. World Health Organization. Introduction of Hepatitis B into Childhood Immunization Services: Management Guidelines, Including Information for Health Workers and Parents. Geneva: WHO, 2001.

7. Odemuyiwa SO, Mulders MN, Oyedele OI et al. Phylogenetic analysis of new hepatitis B virus isolates from Nigeria supports endemicity of genotype $\mathrm{E}$ in West Africa. J Med Virol 2001; 65:463-469.

8. Puoti M, Manno D, Nesta P, Carosi G. Hepaititis $B$ Virus and HIV coinfection in low-income countries: unmet needs. Clin Infect Dis 2008; 46:367-369.

9. Nyirenda M, Beadsworth MBJ, Stephany P, et al. Prevalence of infection with hepatitis B and C virus and coinfection with HIV in medical inpatients in Malawi. J infect 2008; 57:72-77.

10. Iiboudo D, Simpore J, Ouermi D, Bisseye C, Sagna T, Odolini S. Towards the complete eradication of mother -to-child $\mathrm{HIV} / \mathrm{HBV}$ coinfection at Saint Camille Medical Centre in
Burkina Faso, Africa. Braz J Infect Dis 2010; 14:219-224.

11. Forbi JC, Gabadi S, Alabi R, et al. The role of triple infection with hepatitis B virus, hepatitis C virus, and human immunodeficiency virus (HIV) type-1 on CD4+ lymphocyte levels in the highly HIV infected population of North-Central Nigeria. Mem Inst Oswaldo Cruz 2007; 102:535537.

12. Adewole OO, Anteyi E, Ajuwon Z, Wada I, Elegba F, Ahmed P. Hepatitis B and C virus coinfection in Nigerian patients with HIV infection. J Infect Dev Ctries 2009; 3:369-375.

13. Harania RS, Karuru J, Nelson M, Stebbing J. HIV, hepatitis B and hepatitis $\mathrm{C}$ coinfection in Kenya. AIDS 2008; 22:1221-1229.

14. Teltela SP, Matee MI, Munubhi EK. Seroprevalence of hepatitis B and C viral coinfections among children infected with human immunodeficiency virus attending the paediatric HIV care and treatment center at Muhimbili National Hospital in Dar-es-Saaam, Tanzania. BMC Public Health 2007; 7:338-343.

15. Rana C, Gareth R, Dimitra B, Alexandra M, Jedediah R, Angelo D. Viral co-infection among Children Infected with HIV Type 1. Clin Infect Dis 2003; 36:922-924.

16. Toussi ST, Abadi J, Roseenberg M, Levanon D. Prevalence of hepatitis $\mathrm{B}$ and $\mathrm{C}$ virus infections in children infected with HIV. Clin Infect Dis 2007; 45:795-798.

17. Rouet F, Chaix M, Inwoley A, et al. Frequent occurrence of chronic hepatitis $B$ virus infection among West African HIV type 1 infected children. Clin Infect Dis 2008; 46:361-366.

18. Rawizza H, Ochigbo S, Chang C, et al. Prevalence of hepatitis co-infection among HIV infected Nigerian children in the Harvard PEPFAR ART program. Presented at the $17^{\text {th }}$ Conference on Retroviruses and Opportunistic Infections, San Francisco,16-19 Febraury 2010.Poster abstract S181.retroconference.org/2010/abstracts/ 39148htm(accessed 13 May 2010).

19. Pol S, Soriano V. Management of chronic hepatitis $\mathrm{C}$ virus infection in HIV-infected patients. Clin Infect Dis 2008; 47:94-101.

20. Dore GJ, Cooper DA. The impact of HIV therapy on co-infection with hepatitis B and hepatitis C viruses. Curr Opin Infect Dis 2001; 14:749-755 
21. Grenb G. Clinical progression, survival, and immune recovery during antiretroviral therapy in patients with HIV-1 and Hepatitis C virus coinfection: the Swiss HIV Cohort Study. Lancet 2000; 356:1800-1805

22. Rathburn RC, Hockhart SM, Stephen JR. HIV treatment guidelines-An overview. Curr Pharm Dis 2006; 12:1045-1063.

23. Feld JJ, Ocama P. Ronald A. The liver in HIV in Africa. Antivir Ther 2005; 10:953-955.

24. Sadoh AE, Sadoh WE, Iduoriyekemwen NJ. HIV co-infection with hepatitis B and C viruses among Nigerian children in an antiretroviral treatment programme. South African Journal of Child Health 2011; 5(1):7-10.

25. Bukbuk DN, Barsi AP, Mungoro ZM. Seroprevalence of hepatitis surface antigen among primary school pupils in rural Hawal valley, Borno state,Nigeria. Nig J Com Med Pry Health Care 2005; 17:20-23.

26. Brinker M, Wit FW, Wertheim-Van PM et al. Hepatitis $\mathrm{B}$ and $\mathrm{C}$ virus co-infection and the risk for hepatotoxicity of highly active antiretroviral therapy in HIV-1 infection. AIDS 2000; 22:28952902.
27. Alfredo A, Nathan C, Simon C, Wolfram G, Jens L, Giorgio P, Peter R, Rodolphe T, Ola W, Yazdan Y, Stefan Z: Short statement of the first European consensus conference on treatment of chronic hepatitis b and c in HIV co-infected patients. $J$ Hepatol 2005,42:615-624.

28. Torti C, Lapadula G, Casari S, et al. Incidence and risk factors for liver enzyme elevation during highly active antiretroviral therapy in HIV-HCV co-infected patients: result from the Italian EPOKA- MASTER cohort. BMC Infect Dis 2005; $8: 58$

29. Sulkowski MS: Drug-induced liver injury associated with antiretroviral therapy that includes HIV-1 protease inhibitors. Clin Infect Dis 2004; 38:90-97.

30. Sulkowski MS. Management of hepatic complications in HIV - infected persons. J Infect Dis 2008; 197 (Supplement 3) : S279 - S293.

31. Lincoln D, Petoumenos K, Dore GJ. HIV/HBV and HIV/HCV co-infection, and outcomes following highly active antiretroviral therapy. HIV Medicine 2003; 4:241-249. 